\title{
PENGARUH KUALITAS PELAYANAN TERHADAP KEPUASAN KONSUMEN PADA SHOWROOM PERINTIS MOTOR
}

\author{
Ela Fitriadi ${ }^{1}$, Nova Rini2 \\ ${ }^{1}$ STIE Muhammadiyah Jakarta, elafitriadi12@gmail.com \\ ${ }^{2}$ STIE Muhammadiyah Jakarta, nvrin2017@yahoo.com
}

\begin{abstract}
ABSTRAK
Penelitian ini bertujuan untuk menguji pengaruh kualitas pelayanan terhadap kepuasan konsumen pada Showroom Perintis Motor. Penelitian ini menggunakan pendekatan kuantitatif dan desain penelitian yang dipilih oleh penulis adalah Causal Research. Populasi yang akan diteliti adalah konsumen Showroom Perintis Motor yang tidak diketahui jumlahnya, sehingga untuk menghitung jumlah sampel minimum yang dibutuhkan menggunakan rumus perhitungan Hair et al, yang jumlah sampelnya sebesar 115 responden. Teknik pengumpulan data yang digunakan dalam penelitian ini adalah penyebaran kuesioner, observasi dan studi pustaka. Hasil penelitian yang diperoleh menunjukkan bahwa variabel bebas (kualitas pelayanan) memiliki pengaruh positif terhadap variabel terikat (kepuasan konsumen). Konsumen merasa puas dikarenakan karyawan Showroom Perintis Motor melakukan pelayanan yang dikerjakan saat ini, serta mampu memberikan informasi dengan jelas yang ternyata mempengaruhi tingkat kepuasan konsumen. Hasil penelitian tersebut tentunya terdapat kesesuaian terhadap beberapa hasil analisis yang dilakukan oleh penelitian-penelitian terdahulu.
\end{abstract}

Kata Kunci : Kualitas Pelayanan, Kepuasan Konsumen

\section{ABSTRACT}

This study aims to examine the effect of service quality on customer satisfaction in the Showroom Perintis Motor. Research this use approach quantitative and design selected research by author is Causal Research. Population that will researched is consumer Showroom perintis motor who don't is known the amount, so for calculate amount minimum sample needed use formula calculation of Hair et al, whose the number of samples as big as 115 respondents. Technique data collection is used in research this is questionnaire distribution, observation and literature study. The results research obtained show that the independent variable (service quality) has a positive influence on the dependent variable (customer satisfaction). Consumer feel satisfied because of employee Showroom Perintis Motor do service whose done when this, as well able to give information with obviously that turns out influence level satisfaction consumers. The result research aforesaid certainly there are suitability against several result analysis whose done by research-research foregone.

Keywords: Service Quality, Consumer Satisfaction

\section{PENDAHULUAN}

Seiring dengan pembangunan yang dilakukan pemerintah Indonesia, kondisi sosial ekonomi masyarakat juga mengalami perubahan terutama tentang sistem nilai yang dianut dan cara pandang masyarakat. Masyarakat lebih menuntut kualitas pelayanan yang lebih baik dan sesuai dengan kebutuhannya, sehingga mereka lebih teliti dan kritis dalam memilih segala sesuatu yang dapat digunakan untuk memenuhi kebutuhannya (Riswantiana, 2016). 
Diantaranya kebutuhan masyarakat akan alat transportasi, tentunya di era modern seperti saat ini kita sangat membutuhkan transportasi baik darat, laut maupun udara yang dapat cepat melayani kebutuhan konsumen. Untuk kebutuhan transportasi darat, kebutuhan bermotor sangat dibutuhkan (Nugroho, 2016). Besarnya kebutuhan dari setiap orang akan membuat para pengusaha mendirikan usaha dalam bidang kendaraan bermotor baik dalam skala besar maupun skala kecil. Usaha dalam bidang kendaraan bermotor/otomotif yang didirikan oleh masing-masing pengusaha mencakup penjualan mobil/motor. Kebutuhan akan masyarakat terhadap mobil menyebabkan para produsen mobil berlomba-lomba untuk meningkatkan kualitas pelayanan (Service Quality) pada masing-masing perusahaannya (Unsulangi, 2008).

Kualitas memiliki hubungan yang erat dengan kepuasan konsumen. Kualitas akan dilihat sebagai kelemahan bila konsumen mempunyai harapan yang terlalu tinggi dalam menilai jasa yang ditawarkan. Kelemahan lain adalah konsumen tidak tahu dengan kriteria yang digunakan untuk mengevaluasi jasa, dan bila tidak terpenuhi maka akan terjadi kekecewaan terhadap pelayanan jasa tersebut. Jadi perusahaan yang bergerak di bidang jasa harus memenuhi atau melebihi harapan kualitas konsumen.

Untuk menciptakan jasa yang berkualitas perlu menciptakan inovasi-inovasi yang berkelanjutan, dan dengan inovasi yang terus-menerus akan mempertahankan pelanggan. Kepuasan konsumen merupakan faktor penentu dalam strategi pemasaran dan dipastikan sebagai cara yang jitu dalam menghadapi persaingan yang semakin ketat. Kepuasan konsumen merupakan investasi jangka panjang bagi perusahaan, karena banyak manfaat dari terciptanya kepuasan konsumen yaitu, terciptanya hubungan yang harmonis antara perusahaan dengan konsumen, memberikan dasar yang baik untuk pembelian ulang dan terciptanya loyalitas pelanggan dan membentuk rekomendasi dari mulut ke mulut yang menguntungkan bagi perusahaan. Sehingga perusahaan harus menempatkan orientasi pada kepuasan konsumen sebagai tujuan utama kerena kepuasan sebagai penentu keberhasilan kinerja dari suatu perusahaan.

Berdasarkan hasil pengamatan yang peneliti lakukan pada Showroom Perintis Motor kepuasan konsumennya masih sangat rendah. Hal ini ditunjukkan dengan masalah yang terjadi, yaitu : Kesediaan konsumen untuk merekomendasikan jasa pelayanan yang diterima kepada teman dan keluarganya. Contoh : para konsumen yang telah berkunjung kurang merekomendasikan ke teman-teman dan keluarganya disebabkan pelayanan pegawai kurang cepat dan kurang tanggap dengan kritikan dari konsumen (Riswantiana, 2016).Fasilitas ruang tunggu dan tempat parkir kurang memadai. Kamar mandi kurang terjaga kebersihannya. Pelayanan tidak ramah terhadap konsumen (Nugroho, 2016).Saat ini banyak didirikan showroom-showroom pesaing dengan lokasi yang hampir berdekatan, sehingga memberikan alternatif pilihan bagi konsumen untuk melakukan pembelian kendaraan selain di Showroom Perintis Motor, yang kemungkinan memberikan pelayanan yang lebih baik (Anuraga, 2012).

Berbagai penelitian terdahulu tentang Pengaruh Kualitas Pelayanan Terhadap Kepuasan Pelanggan telah banyak dilakukan oleh peneliti sebelumnya dan menghasilkan hasil dan temuan yang beragam. Muklas (2015), Astuti (2016), Ramendra (2016), Puspitasari (2016), dan Rahayu \& Wati (2018) samasama membuktikan hasil positif dimana kualitas pelayanan berpengaruh secara signifikan terhadap kepuasan konsumen. Menurut Basir, dkk (2015) dan Bharwana, dkk (2013) dalam jurnal internasional membuktikan hasil positif dimana kualitas pelayanan berpengaruh secara signifikan terhadap kepuasan konsumen. Namun menurut Yunitasari (2016) dan Yesenia \& Siregar (2014) membuktikan hasil berbeda yaitu negatif dimana kualitas pelayanan tidak berpengaruh signifikan terhadap kepuasan konsumen.

Berdasarkan permasalahan dan latar belakang tersebut, penulis tertarik untuk melakukan penelitian mengenai pengaruh kualitas pelayanan terhadap kepuasan konsumen pada Showroom Perintis Motor.

\section{KAJIAN PUSTAKA Kualitas Pelayanan}


Menurut Tjiptono (2014:268) merumuskan kualitas jasa atau pelayanan sebagai berikut: "Definisi kualitas pelayanan berpusat pada upaya pemenuhan kebutuhan dan keinginan pelanggan serta ketepatan penyampaiannya untuk mengimbangi harapan pelanggan".

Kotler dan Keller (2007:25) menyatakan bahwa kualitas pelayanan harus dimulai dari kebutuhan pelanggan dan berakhir pada persepsi pelanggan, dimana persepsi pelanggan terhadap kualitas pelayanan merupakan penilaian menyeluruh atas keunggulan suatu pelayanan.

\section{Harapan Konsumen Terhadap Kualitas Pelayanan}

Menurut Zeithaml (1996) mengemukakan ada dua tingkat harapan yang menentukan persepsi konsumen terhadap kualitas pelayanan, yaitu:

1. Desired Service, yaitu merupakan tingkat pelayanan yang diharapkan akan diterima konsumen, merupakan gabungan dari apa yang dipercaya akan diterima konsumen dan apa yang seharusnya diterima oleh konsumen

2. Adequate Service, yaitu pelayanan memadai yang merupakan pelayanan minimum yang dapat diberikan oleh perusahaan yang diharapkan dapat memenuhi kebutuhan dasar konsumen.

\section{Kepuasan Konsumen}

Tjiptono (2014:353), menyatakan kepuasan berasal dari bahasa Latin Satis yang berarti cukup baik, memadai dan Facio yang berarti melakukan atau membuat Secara sederhana kepuasan bisa diartikan sebagai upaya pemenuhan sesuatu atau membuat sesuatu memadai.

Menurut Zeithaml dan Bitner (2013:75) definisi kepuasan adalah: Respon atau tanggapan konsumen mengenai pemenuhan kebutuhan. Kepuasan merupakan penilaian mengenai ciri atau keistimewaan produk atau jasa, atau produk itu sendiri, yang menyediakan tingkat kesenangan konsumen berkaitan dengan pemenuhan kebutuhan konsumsi konsumen.

\section{Faktor-Faktor Yang Mempengaruhi Kepuasan Konsumen}

Dalam menentukan tingkat kepuasan konsumen, terdapat lima faktor utama yang harus diperhatikan oleh perusahaan menurut Lupiyoadi (2014: 21) dalam Amanda Permatasari yaitu:

1. Kualitas produk

Konsumen akan merasa puas bila hasil evaluasi mereka menunjukkan bahwa produk yang mereka gunakan berkualitas.

2. Kualitas pelayanan

Terutama untuk industri jasa. Konsumen akan merasa puas bila mereka mendapatkan pelayanan yang baik atau yang sesuai dengan yang diharapkan.

3. Emosional

Konsumen akan merasa bangga dan mendapatkan keyakinan bahwa orang lain akan kagum terhadap dia bila menggunakan produk dengan merek tertentu yang cenderung mempunyai tingkat kepuasan yang lebih tinggi. Kepuasan yang diperoleh bukan karena kualitas dari produk tetapi dari nilai sosial yang membuat konsumen menjadi puas terhadap merek tertentu.

4. Harga

Produk yang mempunyai kualitas yang sama tetapi menetapkan harga yang relatif murah akan memberikan nilai yang lebih tinggi kepada konsumennya.

5. Biaya

Konsumen yang tidak perlu mengeluarkan biaya tambahan atau tidak perlu membuang waktu untuk mendapatkan suatu produk cenderung merasa puas. 


\section{JURNAL EKOBIS: EKONOMI, BISNIS \& MANAJEMEN \\ Volume 9, Nomor 1, Maret (2019)}

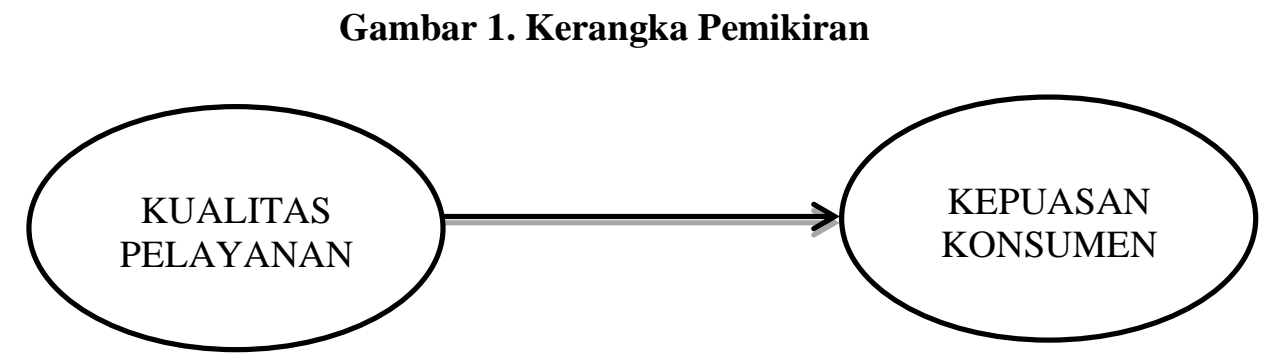

\section{Pengembangan Hipotesis}

Penguji pengaruh Kualitas Pelayanan terhadap Kepuasan Konsumen dengan data empiris telah dilakukan oleh beberapa penelitian terdahulu. Penelitian yang dilakukan oleh Muklas (2015), Astuti (2016), Ramendra (2016), Puspitasari (2016), Basir, dkk (2015) dan Bharwana, dkk (2013), Rahayu dan Wati (2018) menunjukkan bahwa kualitas pelayanan terbukti berpengaruh positif dan signifikan terhadap kepuasan konsumen.

Mengacu pada uraian diatas maka hipotesiss yang dikembangkan adalah sebagai berikut:

H1: Kualitas pelayanan berpengaruh positif dan signifikan terhadap kepuasan konsumen

\section{METODE PENELITIAN}

Penelitian ini menggunakan kuesioner atau angket dan wawancara di wilayah Jakarta Timur dan sekitarnya yang merupakan pelanggan Showroom Perintis Motor bertempat di daerah Cipinang Muara, Jakarta Timur. Penelitian ini menggunakan pendekatan kuantitatif. Populasi pada penelitian ini adalah konsumen Showroom Perintis Motor yang tidak diketahui jumlahnya, sehingga untuk menghitung jumlah sampel minimum yang dibutuhkan menggunakan rumus perhitungan Hair et al (2011) dikutip dalam Wati (2018:96), yaitu jumlah indikator penelitian dikali 5 sampai 10. Dengan demikian sampel untuk penelitian ini adalah:

Jumlah sampel $=$ Jumlah indikator $\mathrm{x} 5$

Jika ada 23 indikator pertanyaan maka jumlah minimum sampel adalah:

$23 \times 5=115$ Sampel

Pada perhitungan berdasarkan rumus diatas jumlah sampel minimum adalah 115 Sampel.

\section{Teknik Analisa Data}

\section{Uji Regresi Linier Sederhana}

Analisis regresi sederhana digunakan untuk mengetahui seberapa besar pengaruh variabel bebas yaitu kualitas pelayanan $(\mathrm{X})$, terhadap variabel terikat yaitu kepuasan konsumen $(\mathrm{Y})$. Adapun rumus regresi sederhana (Ghozali, 2005) adalah:

$$
\mathrm{Y}=\boldsymbol{a}+\boldsymbol{\beta} \mathrm{X}+\mathrm{e}
$$

Keterangan:

$\mathrm{Y}=$ Variabel Terikat (Kepuasan Konsumen)

$\mathrm{X}=$ Variabel Bebas (Kualitas Pelayanan)

$A \quad=$ Konstanta

$B \quad=$ Koefisien garis regresi

e $\quad$ Persen kelonggaran ketidaktelitian karena kesalahan pengambilan

\section{Analisis Koefisien Korelasi}


Koefisien korelasi (r) merupakan alat bantu untuk menjelaskan bagaimana garis regresi menerangkan perubahan (variasi) dari nilai variabel tidak bebas $(\mathrm{Y})$, yaitu kepuasan konsumen. Untuk mencari nilai koefisien korelasi (r) ini digunakan rumus seperti dibawah ini:

$$
r=\frac{n \cdot \sum X Y-\sum X \cdot \sum Y}{\sqrt{\left[n \sum X^{2}-\left(\sum X\right)^{2}\right]\left[n \sum Y^{2}-\left(\sum Y\right)^{2}\right]}}
$$

Nilai koefisien korelasi (r) akan berkisar antara nilai -1 dan nilai +1 . Nilai koefisien positif artinya nilai $\mathrm{r}$ menjelaskan hubungan yang searah. Maksudnya hubungan searah adalah bila variabel bebas (X) meningkat maka variabel tidak bebas (Y) meningkat pula secara proposional dan sebaliknya bila variabel bebas menurun maka variabel tidak bebas akan menurun pula.

Nilai koefisien korelasi (r) negatif, ini berarti nilai $r$ menjelaskan hubungan yang berlawanan. Yang dimaksud dengan hubungan yang berlawanan adalah bila variabel bebas (X) meningkat, maka variabel tidak bebas (Y) secara proposional akan menurun dan sebaliknya bila variabel bebas menurun maka variabel tidak bebas secara proposional akan meningkat. Sedangkan bila nilai koefisien korelasi (r) nilai nol berarti tidak ada hubungan secara statistik antara variabel bebas (X) dengan variabel tidak bebas (Y).

Adapun kriteria untuk memberikan interprestasi koefisien korelasi hubungan antar variabel digunakan pedoman sebagaimana pendapat Soegiono (2011) sebagai berikut:

Tabel 1. Pedoman Interprestasi Koefisien Korelasi

\begin{tabular}{|c|c|}
\hline Niali Mutlak Korelasi & Tingkat Keeratan \\
\hline $0,00-0,199$ & Sangat rendah \\
$0,20-0,399$ & Rendah \\
$0,40-0,599$ & Sedang \\
$0,60-0,799$ & Kuat \\
$0,80-1,000$ & Sangat Kuat \\
\hline
\end{tabular}

Sumber: Soegiono, (2011)

\section{Analisis Koefisien Determinasi}

Koefisien determinasi $\left(\mathrm{R}^{2}\right)$ pada intinya mengukur seberapa jauh kemampuan model dalam menerangkan variasi variabel dependen. Nilai koefisien determinasi adalah antara nol dan satu. Nilai $\mathrm{R}^{2}$ yang kecil berarti kemampuan variabel independen dalam menjelaskan variasi dependen amat terbatas. Nilai yang mendekati satu berarti variabel independen memberikan hampir semua informasi yang dibutuhkan untuk memprediksi variasi variabel dependen. Secara umum koefisien determinasi untuk data silang (crossection) relatif rendah karena adanya variasi yang besar antara masing-masing pengamatan, sedangkan untuk data runtun waktu (timeseries) biasanya mempunyai nilai koefisien determinasi yang tinggi.

Kelemahan mendasar penggunaan koefisien determinasi adalah bias terhadap jumlah variabel independen yang dimasukkan kedalam model. Setiap tambahan satu variabel independen, maka $\mathrm{R}^{2}$ pasti meningkat tidak perduli apakah variabel tersebut berpengaruh secara signifikan terhadap variabel dependen. Oleh karena itu banyak peneliti menganjurkan untuk menggunakan nilai Adjusted $\mathrm{R}^{2}$ pada saat mengevaluasi mana model regresi terbaik. Tidak seperti $\mathrm{R}^{2}$, niali Adjusted $\mathrm{R}^{2}$ dapat naik atau turun apabila satu variabel independen ditambahkan kedalam model.

\section{Uji Hipotesis}

Untuk menguji hipotesis dalam penelitian ini, digunakan nilai $t_{\text {statistik }}$ pada masing-masing jalur pengaruh langsung secara parsial. Untuk menguji hubungan antar variabel (uji hipotesis), maka digunakan 
nilai $t_{\text {statistik }}$ dari output SPSS yang dibandingkan dengan nilai $t_{\text {tabel }}$ dan $t_{\text {tabel }}$ signifikan $5 \%$ sebesar 1.96 (Imam Ghozali, 2014).

Analisa atas koefisien jalur dilakukan dengan menganalisis signifikan besaran regression weight. Analisis ini dilakukan untuk menunjukan besaran dari efek menyeluruh, efek langsung serta efek tidak langsung dari satu variabel terhadap variabel lainnya. Adapun rumusan hipotesis dari besaran regression weight adalah sebagai berikut:

$\mathrm{H}_{0}=\beta \leq 0$ artinya tidak terdapat pengaruh positif signifikan antara variabel independen terhadap variabel dependen.

$\mathrm{H}_{\mathrm{a}}=\beta \geq 0$ artinya terdapat pengaruh positif signifikan antara variabel independen terhadap variabel dependen.

Berdasarkan kajian diatas, penulis membuat rumusan hipotesis yang dirumuskan dari hipotesis yang diajukan dalam penelitian ini yaitu sebagai berikut:

$\mathrm{H}_{0}=$ Tidak terdapat pengaruh positif dan signifikan antara Kualitas Pelayanan terhadap Kepuasan Konsumen.

$\mathrm{H}_{\mathrm{a}}=$ Terdapat pengaruh positif dan signifika nantara Kualitas Pelayanan terhadap Kepuasan Konsumen.

\section{Uji t-statistik (Parsial)}

Uji t digunakan untuk menguji pengaruh variabel independen secara parsial terhadap variabel dependen. Pengujian ini dilakukan dengan uji t pada tingkat keyakinan 95\% dengan ketentuan sebagai berikut:

a. Dengan menggunakan nilai probabilitas signifikansi.

- Jika tingkat signifikansi lebih besar 0,05 maka dapat disimpulkan bahwa $\mathrm{H}_{0}$ diterima, sebaliknya $\mathrm{H}_{\mathrm{a}}$ ditolak.

- Jika tingkat signifikansi lebih kecil 0,05 maka dapat disimpulkan bahwa $\mathrm{H}_{0}$ ditolak, sebaliknya $\mathrm{H}_{\mathrm{a}}$ diterima.

b. Dengan membandingkan thitung dengan tabel

- Jika thitung > t tabel maka $\mathrm{H}_{0}$ ditolak, sebaliknya $\mathrm{H}_{\mathrm{a}}$ diterima, artinya terdapat pengaruh antara dua variabel secara statistik.

- Jika t hitung < t tabel maka $\mathrm{H}_{0}$ diterima, sebaliknya $\mathrm{H}_{\mathrm{a}}$ ditolak, artinya tidak terdapat pengaruh antara dua variabel secara statistik.

\section{HASIL PENELITIAN}

Deskriptif Responden

Responden dalam penelitian ini adalah 115 orang responden (konsumen). Koesioner telah diisi oleh 115 responden, kemudian diolah menjadi data penelitian, berdasarkan data yang diperoleh maka diketahui bahwa jumlah pada semua indikator lengkap dan sesuai dengan jumlah responden.

Distribusi data responden dapat terlihat pada beberapa tabel berikut ini :

1. Berdasarkan Jenis Kelamin

Tabel 2. Jenis Kelamin

\begin{tabular}{|l|c|c|}
\hline \multicolumn{1}{|c|}{ Jenis Kelamin } & Jumlah & Presentase (\%) \\
\hline Laki-Laki & 79 & $69 \%$ \\
\hline Perempuan & 36 & $31 \%$ \\
\hline Jumlah & 115 & $100 \%$ \\
\hline
\end{tabular}

Sumber : Data primer yang diolah 
Berdasarkan table 2. diatas dapat dijelaskan bahwa distribusi responden berdasarkan jenis kelamin yaitu 79 responden dengan presentase $69 \%$ yang berjenis kelamin laki-laki, sedangkan 36 responden dengan presentase $31 \%$ yang berjenis perempuan. Hal ini mengambarkan bahwa jumlah responden laki-laki yang datang ke Showroom Perintis Motor lebih banyak dibandingkan dengan perempuan.

\section{Berdasarkan Umur}

Tabel 3. Umur

\begin{tabular}{|l|c|c|}
\hline \multicolumn{1}{|c|}{ Umur } & Jumlah & Presentase (\%) \\
\hline 18 s/d 25 tahun & 7 & $6 \%$ \\
\hline Diatas 25 s/d 30 tahun & 15 & $13 \%$ \\
\hline Diatas 30 s/d 40 tahun & 43 & $37 \%$ \\
\hline Diatas 40 s/d 50 tahun & 39 & $34 \%$ \\
\hline Diatas 50 & 11 & $10 \%$ \\
\hline Jumlah & 115 & $100 \%$ \\
\hline
\end{tabular}

Sumber : Data primer yang diolah

Berdasarkan tabel 3. diatas dapat dijelaskan bahwa distribusi responden berdasarkan usia yaitu 7 responden dengan presentase $6 \%$ yang berumur $18 \mathrm{~s} / \mathrm{d} 25$ tahun, 15 responden dengan presentase $13 \%$ yang berumur diatas $25 \mathrm{~s} / \mathrm{d} 30$ tahun, 43 responden dengan presentase $37 \%$ yang berumur diatas $30 \mathrm{~s} / \mathrm{d} 40$ tahun, 39 responden dengan presentase $34 \%$ yang berumur diatas $40 \mathrm{~s} / \mathrm{d} 50$ tahun, dan 11 responden dengan presentase $10 \%$ yang berumur diatas 50 tahun.

3. Berdasarkan Pekerjaan

\begin{tabular}{|l|c|c|}
\multicolumn{3}{c}{ Tabel 4. Pekerjaan } \\
\hline \multicolumn{1}{|c|}{ Pekerjaan } & Jumlah & Presentase $(\%)$ \\
\hline Pelajar/Mahasiswa & 7 & $6 \%$ \\
\hline Pegawai Negeri & 33 & $29 \%$ \\
\hline Karyawan Swasta & 17 & $15 \%$ \\
\hline Wiraswasta & 39 & $34 \%$ \\
\hline Lain-Lain & 19 & $16 \%$ \\
\hline Jumlah & 115 & $100 \%$ \\
\hline
\end{tabular}

Sumber : Data primer yang diolah

Berdasarkan tabel 4. diatas dapat dijelaskan bahwa distribusi responden berdasarkan pekerjaan yaitu 7 responden dengan presentase 6\% yang bekerja sebagai pelajar/mahasiswa, 33 responden dengan presentase $29 \%$ yang bekerja sebagai pegawai negeri, 17 responden dengan presentase $15 \%$ yang bekerja sebagai karyawan swasta, 39 responden dengan presentase 34\% yang bekerja wiraswasta, dan 19 responden dengan presentase $16 \%$ yang bekerja sebagai lain-lain.

\section{Deskriptif Variabel Penelitian}

Pada tahap ini akan dilakukan analisis terhadap variabel-variabel penelitian berdasarkan item pertanyaan dalam kuesioner. Variabel kualitas pelayanan terdiri dari sembilan belas indikator yaitu X1 - X19, dan variabel kepuasan konsumen terdiri dari empat indikator pertanyaan yaitu Y1 - Y4. Deskripsi dari variabel-variabel penelitian tersebut dijelaskan pada tabel 4.4 sebagai berikut:

Tabel 5 Deskripsi Variabel Penelitian

\begin{tabular}{|c|c|c|c|c|c|}
\hline $\begin{array}{c}\text { Variabel \& } \\
\text { item }\end{array}$ & STS & TS & RR & S & SS \\
\cline { 2 - 6 } & 1 & 2 & 3 & 4 & 5 \\
\hline
\end{tabular}




\section{JURNAL EKOBIS: EKONOMI, BISNIS \& MANAJEMEN \\ Volume 9, Nomor 1, Maret (2019)}

\begin{tabular}{|c|c|c|c|c|c|c|c|c|c|c|}
\hline pertanyaan & $\mathrm{f}$ & $\%$ & $\mathrm{f}$ & $\%$ & $\mathrm{~F}$ & $\%$ & $\mathrm{f}$ & $\%$ & $\mathrm{f}$ & $\%$ \\
\hline \multicolumn{11}{|c|}{ Kualitas Pelayanan $(\mathrm{X})$} \\
\hline \multicolumn{11}{|c|}{ Reliability/ Kehandalan } \\
\hline $\mathrm{X} 1$ & 0 & 0 & 1 & 0,9 & 1 & 0,9 & 88 & 76,5 & 25 & 21,7 \\
\hline $\mathrm{X} 2$ & 0 & 0 & 1 & 0,9 & 22 & 19,1 & 65 & 56,5 & 27 & 23,5 \\
\hline X3 & 0 & 0 & 9 & 7,8 & 30 & 26,1 & 50 & 43,5 & 26 & 22,6 \\
\hline \multicolumn{11}{|c|}{ Assurance / Kepercayaan } \\
\hline $\mathrm{X} 4$ & 0 & 0 & 0 & 0 & 2 & 1,7 & 73 & 63,5 & 40 & 34,8 \\
\hline $\mathrm{X} 5$ & 0 & 0 & 3 & 2,6 & 18 & 15,7 & 68 & 59,1 & 26 & 22,6 \\
\hline X6 & 0 & 0 & 0 & 0 & 10 & 8,7 & 89 & 77,4 & 16 & 13,9 \\
\hline \multicolumn{11}{|c|}{ Tangibles / Tampilan } \\
\hline X7 & 0 & 0 & 0 & 0 & 2 & 1,7 & 80 & 69,6 & 33 & 28,7 \\
\hline $\mathrm{X} 8$ & 0 & 0 & 2 & 1,7 & 18 & 15,7 & 64 & 55,7 & 31 & 27,0 \\
\hline $\mathrm{X} 9$ & 0 & 0 & 0 & 0 & 5 & 4,3 & 61 & 53,0 & 49 & 42,6 \\
\hline $\mathrm{X} 10$ & 0 & 0 & 0 & 0 & 1 & 0,9 & 77 & 67,0 & 37 & 32,2 \\
\hline \multicolumn{11}{|c|}{ Empahty / Empati } \\
\hline $\mathrm{X} 11$ & 0 & 0 & 0 & 0 & 5 & 4,3 & 80 & 69,6 & 30 & 26,1 \\
\hline $\mathrm{X} 12$ & 0 & 0 & 4 & 3,5 & 28 & 24,3 & 71 & 61,7 & 12 & 10,4 \\
\hline $\mathrm{X} 13$ & 0 & 0 & 5 & 4,3 & 16 & 13,9 & 80 & 69,6 & 14 & 12,2 \\
\hline X14 & 0 & 0 & 0 & 0 & 3 & 2,6 & 79 & 68,7 & 33 & 28,7 \\
\hline \multicolumn{11}{|c|}{ Responsiveness / Ketanggapan } \\
\hline $\mathrm{X} 15$ & 0 & 0 & 1 & 0,9 & 2 & 1,7 & 90 & 78,3 & 22 & 19,1 \\
\hline $\mathrm{X} 16$ & 0 & 0 & 5 & 4,3 & 9 & 7,8 & 75 & 65,2 & 26 & 22,6 \\
\hline $\mathrm{X} 17$ & 0 & 0 & 2 & 1,7 & 9 & 7,8 & 78 & 67,8 & 26 & 22,6 \\
\hline $\mathrm{X} 18$ & 0 & 0 & 7 & 6,1 & 32 & 27,8 & 68 & 59,1 & 8 & 7,0 \\
\hline X19 & 0 & 0 & 5 & 4,3 & 36 & 31,3 & 69 & 60,0 & 5 & 4,3 \\
\hline \multicolumn{11}{|c|}{ Kepuasan Konsumen (Y) } \\
\hline \multicolumn{11}{|c|}{ Kinerja } \\
\hline $\mathrm{Y} 1$ & 0 & 0 & 0 & 0 & 5 & 4,3 & 94 & 81,7 & 16 & 13,9 \\
\hline $\mathrm{Y} 2$ & 0 & 0 & 0 & 0 & 7 & 6,1 & 86 & 74,8 & 22 & 19,1 \\
\hline \multicolumn{11}{|l|}{ Harapan } \\
\hline Y3 & 0 & 0 & 3 & 2,6 & 9 & 7,8 & 87 & 75,7 & 16 & 13,9 \\
\hline Y4 & 0 & 0 & 4 & 3,5 & 15 & 13,0 & 65 & 56,5 & 31 & 27,0 \\
\hline
\end{tabular}

Sumber: SPSS 25.0

Berdasarkan tabel 5. mengenai deskripsi frekuensi mengenai kualitas pelayanan sebagian besar responden memberikan jawaban untuk pertanyaan-pertanyaan berikut ini:

Pertanyaan X1 yang terkait layanan yang diberikan karyawan showroom perintis motor sesuai prosedur, responden memberikan jawaban setuju dengan presentase $76,5 \%$. Pertanyaan X2 yang terkait jasa dilakukan karyawan showroom perintis sesuai waktu yang dijanjikan, responden memberikan jawaban setuju dengan presentase 56,5\%. Pertanyaan X3 yang terkait karyawan showroom perintis motor memberikan informasi dengan benar, responden memberikan jawaban setuju dengan presentase 43,5\%.

Pertanyaan X4 yang terkait karyawan showroom perintis motor ramah dalam melayani pelanggan, responden memberikan jawaban setuju dengan presentase $63,5 \%$. Pertanyaan X5 yang terkait karyawan showroom perintis motor menguasai jasa yang ditawarkan, responden memberikan jawaban 
setuju dengan presentase 59,1\%. Pertanyaan X6 yang terkait keamanan konsumen yang diberikan karyawan showroom perintis motor terjamin, responden memberikan jawaban setuju dengan presentase $77,4 \%$.

Pertanyaan X7 yang terkait kebersihan dan kenyamanan showroom perintis motor, responden memberikan jawaban setuju dengan presentase $69,6 \%$. Pertanyaan X8 yang terkait kebersihan dan kerapian karyawan showroom perintis motor, responden memberikan jawaban setuju dengan presentase $55,7 \%$. Pertanyaan X9 yang terkait kemudahan tempat parkir di showroom perintis motor, responden memberikan jawaban setuju dengan presentase 53,0\%. Pertanyaan X10 yang terkait lokasi showroom perintis motor yang strategis, responden memberikan jawaban setuju dengan presentase $67,0 \%$.

Pertanyaan X11 yang terkait karyawan showroom perintis motor mampu berkomunikasi dengan baik, responden memberikan jawaban setuju dengan presentase 69,6\%. Pertanyaan X12 yang terkait karyawan showroom perintis motor mengetahui keinginan konsumen, responden memberikan jawaban setuju dengan presentase $61,7 \%$. Pertanyaan X13 yang terkait karyawan showroom perintis motor memberikan perhatian khusus terhadap konsumen, responden memberikan jawaban setuju dengan presentase $69,6 \%$. Pertanyaan X14 yang terkait karyawan showroom perintis motor memberikan kemudahan untuk melakukan transaksi, responden memberikan jawaban setuju dengan presentase 68,7\%.

Pertanyaan X15 yang terkait karyawan showroom perintis motor tanggap terhadap keluhan konsumen, responden memberikan jawaban setuju dengan presentase 78,3\%. Pertanyaan X16 yang terkait kecepatan karyawan showroom perintis motor dalam menyelesaikan masalah, responden memberikan jawaban setuju dengan presentase $65,2 \%$. Pertanyaan X17 yang terkait kesediaan karyawan showroom perintis motor membantu konsumen, responden memberikan jawaban setuju dengan presentase $67,8 \%$. Pertanyaan X18 yang terkait karyawan showroom perintis motor berani mengambil tindakan tepat dan akurat, responden memberikan jawaban setuju dengan presentase 59,1\%. Pertanyaan X19 yang terkait karyawan showroom perintis motor meminimalisasikan kemungkinan terjadinya kesalahan, responden memberikan jawaban setuju dengan presentase $60,0 \%$.

Berdasarkan tabel 4.4 mengenai deskripsi frekuensi mengenai kepuasan konsumen sebagian besar responden memberikan jawaban untuk pertanyaan-pertanyaan berikut ini:

Pertanyaan Y1 yang terkait kepuasan atas kemampuan karyawan showroom perintis motor dalam melayani konsumen dengan tepat, responden memberikan jawaban setuju dengan presentase $81,7 \%$. Pertanyaan Y2 yang kepuasan atas kesigapan karyawan showroom perintis motor dalam melayani konsumen, responden memberikan jawaban setuju dengan presentase 74,8\%.

Pertanyaan Y3 yang terkait kepuasan atas terpenuhinya keinginan konsumen, responden memberikan jawaban setuju dengan presentase $75,7 \%$. Pertanyaan Y4 yang terkait kepuasan atas kemampuan karyawan showroom perintis motor dalam melayani konsumen dibandingkan dengan pesaing, responden memberikan jawaban setuju dengan presentase $56,5 \%$.

\section{Uji Kualitas Instrumen Penelitian Hasil Uji Validitas}

Validitas adalah suatu ukuran yang menunjukkan tingkat keabsahan (valid) suatu alat ukur. Suatu alat ukur yang valid akan memiliki validitas yang tinggi dan begitu juga sebaliknya. Sebuah alat ukur dikatakan valid apabila mampu mengukur data dari obyek yang diinginkan. Tinggi rendahnya alat ukur menunjukkan sejauh mana data yang terkumpul tidak menyimpang dari gambaran tentang variabel yang dimaksud.

Untuk mengetahui apakah kuesioner yang dibuat valid atau belum, maka diadakan uji validitas dengan menguji 115 responden dan hasilnya diolah dengan menggunakan korelasi product moment oleh Pearson. Dalam penelitian ini, peneliti menggunakan SPSS sebagai alat bantu perhitungan statistik. Hasil uji (output) dari SPSS secara otomatis menunjukkan mana butir yang valid dan mana yang tidak valid. 
Tabel 6. berikut adalah hasil perhitungan validitas setiap pertanyaan yang dikelompokkan berdasarkan setiap variabelnya:

Tabel 6. Hasil Uji Validitas

\begin{tabular}{|c|c|c|c|}
\hline Pertanyaan & $\begin{array}{c}\text { Person } \\
\text { Correlation } \\
\end{array}$ & Sig & Keterangan \\
\hline \multicolumn{4}{|l|}{ Kualitas Pelayanan (X) } \\
\hline $\mathrm{X} 1$ & 0,544 & 0,000 & Valid \\
\hline $\mathrm{X} 2$ & 0,685 & 0,000 & Valid \\
\hline $\mathrm{X} 3$ & 0,622 & 0,000 & Valid \\
\hline \multicolumn{4}{|l|}{ Assurance/ Kepercayaan } \\
\hline $\mathrm{X} 4$ & 0,523 & 0,000 & Valid \\
\hline $\mathrm{X} 5$ & 0,611 & 0,000 & Valid \\
\hline X6 & 0,396 & 0,000 & Valid \\
\hline \multicolumn{4}{|l|}{ Tangibles/Tampilan } \\
\hline X7 & 0,258 & 0,005 & Valid \\
\hline $\mathrm{X} 8$ & 0,147 & 0,118 & Tidak \\
\hline X9 & 0,466 & 0,000 & Valid \\
\hline $\mathrm{X} 10$ & 0,422 & 0,000 & $\begin{array}{l}\text { Valid } \\
\text { Valid }\end{array}$ \\
\hline \multicolumn{4}{|l|}{ Empahty/Empati } \\
\hline $\mathrm{X} 11$ & 0,563 & 0,000 & \\
\hline $\mathrm{X} 12$ & 0,400 & 0,000 & Valid \\
\hline $\mathrm{X} 13$ & 0,453 & 0,000 & Valid \\
\hline $\mathrm{X} 14$ & 0,435 & 0,000 & $\begin{array}{l}\text { Valid } \\
\text { Valid }\end{array}$ \\
\hline \multicolumn{3}{|l|}{ Responsiveness/Ketanggapa } & \\
\hline $\mathrm{X} 15$ & 0,649 & 0,000 & Valid \\
\hline $\mathrm{X} 16$ & 0,566 & 0,000 & Valid \\
\hline $\mathrm{X} 17$ & 0,537 & 0,000 & Valid \\
\hline $\mathrm{X} 18$ & 0,499 & 0,000 & Valid \\
\hline X19 & & & Valid \\
\hline \multicolumn{4}{|l|}{ Kepuasan Konsumen (Y) } \\
\hline \multicolumn{4}{|l|}{ Kinerja } \\
\hline Y1 & 0,598 & 0,000 & Valid \\
\hline $\mathrm{Y} 2$ & 0,680 & 0,000 & Valid \\
\hline \multicolumn{4}{|l|}{ Harapan } \\
\hline Y3 & 0,757 & 0,000 & Valid \\
\hline Y4 & 0,803 & 0,000 & Valid \\
\hline
\end{tabular}

Sumber: Data primer yang telah diolah, 2018

\section{Hasil Uji Reliabilitas}


Uji reliabilitas adalah suatu nilai yang menunjukkan konsistensi suatu alat pengukur (indikator pada masing-masing variabel yang digunakan didalam penelitian) dalam mengukur gejala yang sama. Suatu alat ukur dikatakan reliabel apabila dapat memberikan hasil pengukuran yang relatif konsisten, manakala alat ukur tersebut digunakan untuk mengukur gejala yang sama.

Untuk mengukur reliabelitas instrumen pada penelitian ini, digunakan teknik Alpha Cronbach untuk mengetahui indikator atau pertanyaan apa yang harus dihapus atau dihilangkan guna mendapatkan nilai reliabilitas yang baik. Uji reliabilitas dilaksanakan dengan melihat nilai Alpha Cronbach dari tiaptiap indikator dalam instrumen.

Berdasarkan hasil pengujian reliablitias terhadap 115 responden melalui media kuesioner dan menggunakan alat bantu hitung SPSS Berikut adalah hasil perhitungan terhadap uji reliabilitas masingmasing butir pertanyaan:

Tabel 7. Hasil Uji Reliabilitas

\begin{tabular}{|l|c|c|}
\hline \multicolumn{1}{|c|}{ Variabel } & Cronbach's Alpha & Keterangan \\
\hline Kualitas Pelayanan & 0,837 & Reliabel \\
\hline Kepuasan Konsumen & 0,670 & Reliabel \\
\hline
\end{tabular}

Sumber: Data primer yang telah diolah, 2018

Dengan perhitungan uji reliabilitas untuk variabel kualitas pelayanan dan kepuasan konsumen masing-masing diperoleh hasil nilai alpha 0,837 dan 0,670. Dengan demikian semua butir pertanyaan yang digunakan mempunyai Cronbach's Alpha diatas 0,60. Sehingga pertanyaan pada penelitian ini adalah reliabel karena memiliki tingkat konsisten yang handal untuk dipakai (jawaban responden adalah konsisten sehingga dapat dijadikan sebagai alat ukur dalam mengukur variabel penelitian).

\section{Pengujian Hipotesis}

\section{Hasil Uji Regresi Linier Sederhana}

Uji regresi linier sederhana digunakan dalam penelitian ini dengan tujuan untuk membuktikan hipotesis mengenai pengaruh variabel kualitas pelayanan secara parsial maupun secara bersama-sama terhadap kepuasan konsumen Showroom Perintis Motor. Hasil pengolahan data dengan menggunakan program SPSS selengkapnya ada pada lampiran dan selanjutnya dijelaskan pada tabel 8

Tabel 8. Hasil Uji Regresi Linier Sederhana

Kualitas Pelayanan Terhadap Kepuasan Konsumen

Coefficients $^{\mathrm{a}}$

\begin{tabular}{|l|l|r|r|r|r|r|}
\hline \multicolumn{2}{|l|}{ Model } & \multicolumn{2}{|c|}{$\begin{array}{c}\text { Unstandardized } \\
\text { Coefficients }\end{array}$} & $\begin{array}{c}\text { Standardize } \\
\text { d } \\
\text { Coefficients }\end{array}$ & \multirow{2}{*}{ Sig. } & \\
\cline { 2 - 6 } \multicolumn{2}{|c|}{} & B & $\begin{array}{c}\text { Std. } \\
\text { Error }\end{array}$ & Beta & & \\
\hline 1 & (Constant) & 4,685 & 1,642 & & 2,854 &, 00 \\
& X &, 159 &, 022 &, 555 & 7,098 &, 00 \\
& & & & & & 0 \\
\hline
\end{tabular}

a. Dependent Variable: Y

Sumber: Data primer yang telah diolah, 2018

Dari tabel diatas dapat dibuat persamaan regresi sebagai berikut:

$$
\mathrm{Y}=4.685+0,159 \mathrm{X}
$$

Konstanta ( $a$ ) sebesar 4.685 menyatakan bahwa jika tidak ada variabel bebas (kualitas pelayanan) atau variabel bebas bernilai nol, maka kepuasan konsumen akan tetap (konstan) sebesar 4.685. Sedangkan 
koefisien regresi $\mathrm{X}$ sebesar 0,159 memiliki pengertian bahwa jika variabel bebas (kualitas pelayanan) meningkat satu kali akan meningkatkan kepuasan konsumen sebesar 0,159.

\section{Hasil Uji Koefisien Korelasi}

Koefisien korelasi menunjukkan suatu hubungan yang erat antara variabel bebas kualitas pelayanan (X) dengan variabel terikat kepuasan konsumen (Y). Hasil pengolahan data dengan menggunakan program SPSS selengkapnya ada pada lampiran dan selanjutnya dijelaskan pada tabel 9.

Tabel 9. Koefisien Korelasi

\begin{tabular}{|c|c|}
\hline Model & $\mathrm{R}$ \\
\hline Kualitas Pelayanan &, $555^{\mathrm{a}}$ \\
\hline
\end{tabular}

Sumber: Data primer yang telah diolah, 2018

Dari perhitungan statistik di atas diperoleh nilai $r=0,555$. Artinya, dapat disimpulkan bahwa pada fungsi kualitas pelayanan terdapat korelasi yang cukup atau sedang dan nyata (signifikan) antara pengaruh kualitas pelayanan terhadap kepuasan konsumen. Karena dengan nilai $r=0,55$ sesuai dengan tabel interprestasi koefisien korelasi, hubungan antara variabel kualitas pelayanan dengan kepuasan konsumen tersebut dikategorikan sedang atau cukup.

\section{Hasil Uji Koefisien Determinasi}

Hasil pengolahan data dengan menggunakan program SPSS selengkapnya ada pada lampiran dan selanjutnya dijelaskan pada tabel 10

\section{Tabel 10. Koefisien Determinasi} Model Summary ${ }^{b}$

\begin{tabular}{|c|c|c|c|c|c|c|}
\hline & \multirow[b]{3}{*}{$\mathrm{R}$} & \multirow{2}{*}{\multicolumn{3}{|c|}{ pouer summary }} & \multirow{2}{*}{\multicolumn{2}{|c|}{ Change Statistics }} \\
\hline \multirow[b]{2}{*}{ Model } & & & & & & \\
\hline & & R Square & $\begin{array}{l}\text { Adjusted } \\
\text { R Square }\end{array}$ & $\begin{array}{l}\text { Std. Error of } \\
\text { the Estimate }\end{array}$ & $\begin{array}{l}\text { R Square } \\
\text { Change }\end{array}$ & F Change \\
\hline 1 &, $555^{\mathrm{a}}$ & ,308 & ,302 & 1,338 &, 308 & 50,388 \\
\hline
\end{tabular}

Sumber: Data primer yang telah diolah, 2018

Dari perhitungan statistik di atas diperoleh nilai $\mathrm{r}^{2}$ (R Square) adalah sebesar 0,308 hal ini berarti 30,8\% kepuasan konsumen dipengaruhi oleh kualitas pelayanan dan sisanya disebabkan oleh faktor-faktor lain di luar penelitian. Sebagian besar peneliti juga menggunakan Adjusted $R$ Square untuk analisis goodnes of fit model, berdasarkan output SPSS, niali Adjusted R Square sebesar 0,302 atau 30,2\% artinya kepuasan konsumen dipengaruhi oleh kualitas pelayanan sebesar 30,2\% dan sisanya sebesar 60,8\% disebabkan oleh faktor-faktor lain diluar model penelitian.

\section{Hasil Uji Signifikasi Pengaruh Parsial (Uji T)}

Uji t digunakan untuk menguji dan mengetahui signifikansi pengaruh variabel kualitas pelayanan (X) terhadap kepuasan konsumen (Y). Berdasarkan hasil perhitungan dengan software SPSS diperoleh hasil sebagai berikut:

Tabel 11. Uji Hipotesis (Uji t)

\begin{tabular}{|c|c|c|c|c|}
\hline Variabel & $\mathrm{t}$ hitung & $\mathrm{t}$ tabel & $\mathrm{Sig}$ & Keterangan \\
\hline Kualitas pelayanan & 7.098 & 1.658 & 0,000 & Signifikan \\
\hline
\end{tabular}

Sumber: Data primer yang telah diolah, 2018 


\section{JURNAL EKOBIS: EKONOMI, BISNIS \& MANAJEMEN}

Volume 9, Nomor 1, Maret (2019)

Dari perhitungan uji t diatas diperoleh nilai t hitung sebesar 7.098. Dengan level of significience sebesar $5 \%$ dan $\mathrm{df}=\mathrm{n}-2$, berarti $115-2=113$ maka nilai t tabel diatas adalah 1.658. Maka dengan demikian $\mathrm{t}$ hitung > t tabel $(7.098>1.658)$ dan nilai probabilitas signifikansi lebih kecil dari 0,05 yaitu sebesar 0,000. Maka dapat disimpulkan bahwa $\mathrm{H}_{0}$ ditolak, sebaliknya $\mathrm{H}_{\mathrm{a}}$ diterima, dengan kata lain yaitu terdapat hubungan yang signifikan antara variabel kualitas pelayanan dengan kepuasan konsumen.

\section{PEMBAHASAN}

Hasil uji t (uji parsial) hipotesis yang menyatakan bahwa variabel $\mathrm{X}$ (kualitas pelayanan) berpengaruh positif terhadap variabel Y (kepuasan konsumen) pada Showroom Perintis Motor. Konsumen merasa puas dikarenakan karyawan Showroom Perintis Motor melakukan pelayanan yang dikerjakan saat ini, serta mampu memberikan informasi dengan jelas yang ternyata mempengaruhi tingkat kepuasan konsumen. Hasil penelitian ini mendukung penelitian terdahulu yang dilakukan oleh Muklas (2015), Astuti (2016), Ramendra (2016), Bharwana, dkk (2013), Basir, dkk (2015) dan Mohamad, dkk (2017) yang menyatakan variabel $\mathrm{X}$ (kualitas pelayanan) berpengaruh positif dan signifikan terhadap variabel $\mathrm{Y}$ (kepuasan konsumen).

\section{PENUTUP}

\section{Kesimpulan}

Secara keseluruhan, konsumen Showroom Perintis Motor menilai bahwa pelayanan yang diberikan telah sesuai dengan harapan. Hal ini dibuktikan dengan penilaian mayoritas dengan skor persentase pada tabel penilaian terhadap kualitas pelayanan. Tingkat kepuasan konsumen Showroom Perintis Motor berdasarkan tanggapan responden adalah sudah memenuhi harapan. Hal ini dibuktikan dengan penilaian mayoritas dengan skor persentase pada tabel penilaian terhadap kepuasan konsumen. Hasil uji t (uji parsial) hipotesis yang menyatakan bahwa variabel $X$ (kualitas pelayanan) berpengaruh positif terhadap variabel Y (kepuasan konsumen) pada Showroom Perintis Motor. Konsumen merasa puas dikarenakan karyawan Showroom Perintis Motor melakukan pelayanan yang dikerjakan saat ini, serta mampu memberikan informasi dengan jelas yang ternyata mempengaruhi tingkat kepuasan konsumen.

\section{Saran}

Diharapkan karyawan Showroom Perintis Motor dapat mempertahankan dan meningkatkan penampilan, tutur kata, dan sikap profesionalitas dalam memberikan pelayanan. Agar kepuasan konsumen terpenuhi dengan baik, pihak manajemen puncak harus mempertimbangkan untuk memberikan imbalan yang memadai kepada karyawan dan mengelola pelayanan dengan baik. Dengan adanya sistem pelayanan yang baik, maka karyawan akan merasa dihargai dengan pantas, dan dengan perasaan seperti itu akan menimbulkan etos kerja yang tinggi.

\section{DAFTAR PUSTAKA}

Anuraga, Ririh, MP. 2012. “Analisis Service Quality Terhadap Kepuasan Konsumen (Studi Pada PT. Jaya Abadi, Jl. Matraman No. 603 Di Semarang)". http://eprints.undip.ac.id/37008/1/ANURAGA.pdf, diakses 17 Mei 2018.

Astuti, Destini. 2016. "Pengaruh Kualitas Produk dan Kualitas Pelayanan Terhadap Kepuasan Konsumen Di Treeangelo Coffe, Kemang”. Skripsi. STIE Muhammadiyah: Jakarta. (Tidak dipublikasikan). 
Basir, Muhammad, et. al. 2015. "Effect Of Service Quality, Orientation Service And Pricing On Loyalty And Customer Satisfaction In Marine Transportation Services". International Journal Of Humanities And Social Science Invention, Volume 4, Isuue 6, Juni 2015, PP.01-06. http://www.ijhssi.org/papers/v4(6)/Version-2/A04620106.pdf, diakses 13 Juli 2018.

Bharwana, Tariq Khalil. 2013. Impact Of Service Quality On Customers' Satisfaction: A Study From Service Sector Especially Private Colleges Of Faisalabad, Punjab, Pakistan". International Journal Of Scientific And Research Publications, Volume 3, Issue 5, May 2013. http://www.ijsrp.org/research-paper-0513/ijsrp-p1768.pdf, diakses 12 Juli 2018.

Ghozali, Imam. 2018. “Aplikasi Analisis Multivariate Dengan Program IBM SPSS 25, Edisi 9". Penerbit Universitas Diponegoro.

Kotler dan Keller. 2007. Manajemen Pemasaran. Edisi 12 Jilid 2. Indeks, Jakarta.

Muklas, Muhamad. 2015. "Pengaruh Kualitas Pelayanan Customer Service Terhadap Tingkat Kepuasan Nasabah Di Bank BII Maybank Cabang Danau Sunter Utara”. Skripsi. STIE Muhammadiyah: Jakarta. (Tidak dipublikasikan).

Mohamad, Hassan Abbas Dost, et.al. 2017. "Service Quality, Customer Satisfaction And Costumer Loyalty Of The Hotel Industry In United Arab Emirates (UAE): A Measurement Model'. European Journal Of Management and Marketing Studies, Volume 2, Issue 4, 2017. https://oapub.org/soc/index.php/EJMMS/article/view/264/770, diakses 25 Juli 2018.

Nugroho, Muhammad Fakhri. 2016. "Pengaruh Service Quality Terhadap Kepuasan Konsumen

Honda Utama

Motor

Yogyakarta".http://eprints.uny.ac.id/39195/1/MuhammadFakhriNugroho_12808144054.pd f, diakses 12 Mei 2018.

Permatasari, A. (2018). PENGARUH KUALITAS PELAYANAN DAN HARGA TERHADAP KEPUASAN PELANGGAN JASA GO-JEK DI KOTA BANDUNG (Survey pada Mahasiswa-Mahasiswi Fakultas Ekonomi dan Bisnis Universitas Pasundan Bandung) (Doctoral dissertation, Fakultas Ekonomi dan Bisnis Unpas Bandung).

Puspitasari, Selvi. 2016. "Pengaruh Kualitas Pelayanan Terhadap Kepuasan Pelanggan PT. Shellindo Jaya”. Skripsi. STIE Muhammadiyah: Jakarta. (Tidak dipublikasikan).

Ramendra, Rezky. 2016. "Pengaruh Kualitas Layanan Dan Kualitas Makanan Terhadap Kepuasan Dan Loyalitas Konsumen Dengan Peran Moderasi Dari Atmosfer Pada Restoran Etnik, Studi Kasus: Sushi Tei”. Skripsi. Universitas Indonesia: Jakarta. (Tidak dipublikasikan).

Rahayu, Sri., Wati, Lela Nurlaela. 2018. Pengaruh Pengaruh Kualitas Pelayanan Terhadap Kepuasan Pelanggan Dan Dampaknya Terhadap Loyalitas Pelanggan. Jurnal EKOBIS, Ekonomi, Bisnis dan Manajemen. Vol. 8. No. 2. Pp. 154-173.

Riswantiana, Tiara Ayu. 2016. "Pengaruh Kualitas Pelayanan Terhadap Kepuasan Konsumen Pada Showroom Anugrah Pratama Motor Kota Bogor". http://repository.unpas.ac.id/14979/, diakses 11 Mei 2018.

Tjiptono, Fandy. 2014 Pemasaran Jasa. Gramedia Cawang. Jakarta

Unsulangi, Richy Stanley. 2008. "Pengaruh Kualitas Jasa Terhadap Kepuasan Konsumen Bengkel Toyota (Auto 2000) Cabang Sudirman". Skripsi. Universitas Indonesia: Jakarta. (Tidak dipublikasikan). 


\section{JURNAL EKOBIS: EKONOMI, BISNIS \& MANAJEMEN \\ Volume 9, Nomor 1, Maret (2019)}

Wati, Lela Nurlaela. 2018. "Metodologi Penelitian Terapan, Aplikasi SPSS, Eviews, Smart PLS dan AMOS”. Penerbit CV. Pustaka Amri: Bekasi Barat.

Yesenia dan Siregar, Edwar H. 2014. "Pengaruh Kualitas Layanan Dan Produk Terhadap Kepuasan Serta Loyalitas Pelanggan KFC Di Tangerang Selatan”. http://journal.ipb.ac.id/index.php/jmo/article/view/12166/9370, diakses 23 Juli 2018.

Yunitasari, Dian. 2016. "Pengaruh Produk, Harga dan Kualitas Pelayanan Terhadap Kepuasan Konsumen Pada Restaurant KFC". Jurnal Ilmu dan Riset Manajemen: Volume 5, Nomor 6, Juni 2016. https://ejournal.stiesia.ac.id/jirm/article/view/1576/1535, diakses 23 Juli 2018 .

Zeithaml dan Bitner, M. J. 2013. Service Marketing, Sixth Edition. Mc Graw Hill. America 